\title{
Issues and Guidance in Research Ethics
}

\author{
Ronald Francis and Anona Armstrong \\ Victoria University, Australia
}

\begin{abstract}
This paper addresses the principles that govern the outlook and decisions of research ethics committees. The purpose of the paper is to outline such underlying principles in order to aid understanding for researchers into aspects of social and commercial behaviour. Prior to conducting research in any corporate area there is an obligation toward any human participants. That obligation is set out most clearly in the information and forms put out by the various ethics committees charged with examining the proposal, and with giving formal ethical approval. The principles that invest the understanding of ethics committees are those of protecting the vulnerable, and of protecting justifiably good reputations. Ethics committees should be seen as enabling and protecting rather than as a barrier to research. Peer reviews should be seen to include ethics matters in research, and are thus a natural extension of the common scientific endeavour. To this end the article outlines and discusses the issues commonly addressed by research ethics committees. By highlighting these principles, this paper aims to give insights and suggestions that should make the ethics application task easier.
\end{abstract}

\section{Keywords}

University research, research ethics, ethics committees.

\section{Introduction}

Prior to conducting research in any corporate area there is an obligation to any human participants. That obligation is set out most clearly in the information and forms put out by the various ethics committees charged with examining the proposal, and of giving formal ethical approval.

A few researchers see having to seek ethical clearance as a burden. The persuasive arguments against such a view are: that clearance protects the vulnerable; helps preserve reputations; provides evidence of care and thus is a legal protection against unjust accusations, and may provide useful feedback from the committee on matters not of direct ethical import. This article provides an expert perspective on the issues that confront research ethics committees.

A formal statement of the principles that should underlie the notion of protecting the vulnerable arose from the Nuremburg War Trials, and is thus called the Nuremburg Code (see website reference list). It is not surprising that the principles should have emanated from that source as that War Crimes court dealt with such atrocities as the unsanctioned medical experiments on the unwilling. No matter what the

Copyright (C) 2007 Victoria University. This document has been published as part of the Journal of Business Systems, Governance and Ethics in both online and print formats. Educational and non-profit institutions are granted a nonexclusive licence to utilise this document in whole or in part for personal or classroom use without fee, provided that correct attribution and citation are made and this copyright statement is reproduced. Any other usage is prohibited without the express permission of the overall benefit might be, the principle that individuals have their own rights which the interests of the masses should not overturn: those principles are now enshrined in the Nuremburg Code.

The subtitle of the Nuremburg Code is Directives for Human Experimentation. That Code has found more recent expression in the National Health and Medical Research Council (NH\&MRC) 
Code in Australia. This latter Code was, originally, one that dealt mainly with biological and medical research. As it developed over time it has now extended to encompass areas far beyond medical research, and is likely to become the new Australian national standard. (see website reference list).

The principles that invest the understanding of ethics committees are those of thus protecting the vulnerable; we might also add the protection of reputations. Where such protection is justified, it is an important secondary principle.

\section{Ethics Research Committees}

Approval to conduct research is given by several kinds of institutions. One kind is that of one's employing institution; a second kind is the institution which is the target of, or involved in, the research project. For example, one might work for a research institute, and thus need their clearance: the subject of the research might be governance in hospitals, and thus one would also need clearance from the relevant hospital ethics committee. The point here is to consider whether or not one needs more than one clearance.

A fairly rare but illustrative case is one where a researcher from a university might be interested in working on surgical operations on prisoners. In such a case clearance would be needed from the university committee, the relevant hospital research ethics committee, and the relevant Department of Justice. Again, the point being that a single clearance might not suffice. Although a project may require multiple clearances the question remains as to which clearance takes precedence. In practice none do. The only fairly clear principle is that no ethics committee should be in breach of the general principles of the NH\&MRC Code.

Each research ethics committee has a set Terms of Reference. This is both an enabling and a limiting document. It states the powers of the Committee and the limits within which it operates. One would hope that the website or document is a model of clarity of both purpose and of process. To this end most committees use a standard form that is constantly reviewed.

Most research ethics committees are comprised of a carefully chosen number of people. One for business would, for example, have a lawyer, a layperson, a Minister or Aboriginal Elder, an experienced researcher, and someone with formal business qualifications, a lay person with no connection to the business, and whoever else they deem appropriate. It is interesting to note that most committees are comprised of more than five and fewer than 10 members. This may have to do with the dynamics of committees. Too small a group deprives the discussion of needed expertise, and allows strong characters too dominant a role: too many members prevents the prospect of closer collegial discussion, and the development of general collegiality. It may be that the ideal size of group has more to do with the psychology of group relations than anything else - and that is no bad thing.

Some committees have a policy on payment or non-payment of participants. It is interesting to note that too small a sum in payment actually inhibits participation. Too large a sum produces participants who are money rather than science oriented, and might thus skew the results. Another option is not to allow payment to participants, but to take considerable trouble to explain how their participation is a benefit to us all, and that they will receive feedback at the end of the project. What is less controversial is the idea that they be reimbursed out of pocket expenses - such as travel.

There are a number of studies that address this issue. For example, Fry et al. (2005) reported an empirical study of practices of payment, and concluded that ethics committees do spend quite some time on deciding whether or not it is appropriate to pay: to that end a policy on payment is a real committee time saver. Out of pocket expenses are not commonly seen as controversial, nor should they be. Payment for time spent is more controversial.

One may pay participants, but the effects of payment are problematical, as Brown et al. (2006) have argued. Further, one may pay in kind (PinK - payment in kind). That issue was addressed by Schonfeld et al. (2003), who concluded that PinK is a restriction of choice. Cash is universal, and may be used by 
all to maximise value: the use of PinK is a compromise of autonomy. We do conclude that ethics committees do need clear policies with respect to payment.

\section{Principles of Ethics Committees}

It is a useful, and largely accurate, assumption that ethics committees are there to protect the vulnerable and, in so doing, act as enabling bodies. It is not uncommon in that enabling frame of mind to find that committees might recommend some changes in the research design in order to make it more effective. In such cases they are really acting as a bonus advisory body which fosters good research. The main brief to protect the vulnerable is supplemented by the need to protect reputations.

The breach most commonly committed here is that of having a research design that will not answer the posed questions, or has such a committed political view as to render the research a waste of participants' time. The writers have seen research designs that do not permit conclusions based on evidence; that clearly have a committed political agenda; and which are not framed in a form that makes a hypothesis potentially falsifiable.

In addition to the already mentioned principles, committees are also mindful of the need to protect the researchers themselves. For example, one might be interested in (say) a governance project which involves some research in courts. As courts are under the jurisdiction of the Department of Justice, one would thus seek their clearance. Additionally, however, it would be essential to seek the permission of the chief judge of the relevant court. Without such permission researchers could well find themselves in a position of having to defend themselves against an accusation of interfering with the judicial process. Thus it is essential that expert legal advice be sought.

One of the lesser functions of ethics committees is to have a mind which groups, categories, or institutions might be over-researched. Too much research attention could not only have an adverse impact on the functioning of the institution but could also make the respondents within it atypical by being the focus of excessive attention. Further, the intrusions into staff time and into routine procedures may produce a low level of co-operation.

\section{What is Research?}

It is difficult to define what is research: one working definition might be 'Creative work undertaken on a systematic basis in order to increase the stock of knowledge, including knowledge of humanity, culture and society. Research is not just about finding facts but, rather, of using hard core data to evaluate certain conceptual explanations. This stock of conceptual insights is then used to devise improved versions, and to make new connections' This definition is one that is a composite of several others already in the public domain.

In order to do research involving humans or animals it is necessary to have ethics clearance. Sometimes research masquerades as something else - such as ongoing monitoring, teaching research techniques, or routine data collection. In the words of the Department of Education, Science, and Training (DEST) 'Research and experimental development is characterised by originality; it should have investigation as a primary objective and should have the potential to produce results that are sufficiently general for humanity's stock of knowledge (theoretical and/or practical) to be recognisably increased'.

Research is an activity designed to gain new insights into phenomena, but using that highly general rubric is not a lot of help. Some research may be theory driven; some may use a grounded theory approach; and some may be simply heuristic. Project management, program evaluation, training, and monitoring are not commonly seen as research although, given a particular twist, they become so. What may be more helpful would be to say what it is not. Some of the things that may look like research, but are not, include:

- Preparation for teaching (e.g. the collection of information about which kind of students responded best to a mentoring program) 
- Routine data collection (e.g. public domain statistics on certain events, such as how often it rained on Melbourne Cup Day - handy if you want to estimate the risks of writing pluvius insurance)

- Routine computer programming (such as how much use is made of particular websites, and if any employee has accessed a pornographic site)

- Standardised testing (such as essential routine medical testing for employees)

- Business tracking (such as whether or not board meetings are more productive if they have a concise, or an extended, agenda).

It will be seen that the question 'What is research' is represented by answers that show it to be a broad church. A general guide to what research is, may be found on the DEST website.

\section{What is Data?}

It is important to define what data is, because committees have a duty about the retention of data for a given period of years as a means of checking authenticity. Data is the information collected, and that is raw (untreated) data. As a special case one can imagine a situation in which verbal responses are recorded. Some participants may be happy to have their responses used for analysis, but unwilling to have the voice recordings remain, as the timbre of voice is an identifier.

In such circumstances the responses may be transcribed word-for-word, and have that written verbatim data treated as (primary) raw data. The undertaking of anonymity is the reason for transcribing. In principle it is recommended that data in its most raw form be retained, and only in special circumstances, such as the above, be treated in any way. The guiding principle is that the further one gets from the basic form of data the more likelihood there is of error.

\section{Conflict of Interest}

A conflict of interest may be defined as '.. where a person is in a position such that a fact, a belief, a power, or a perception, exists that might compromise their objectivity'. In ethics committees, where a member of the committee has a beneficial interest in the outcome then he or she will absent themself not only for the vote but also for the deliberations which precede the vote. We recognise that the mere presence in the committee room may be an inhibitor to open discussion. In this way fairness is not only done but also seen to be done.

\section{Deception}

A significant issue here is that of deception. In one study Epley \& Huff (1998) assessed reactions to debriefing after a deception experiment. The general finding of that study was that although a large effect of deception was not found it did show that negative feedback had a detrimental effect. The cautionary conclusion here is that negative stimuli and suspicion are factors to be avoided.

In marketing research it is not uncommon for researchers to deceive respondents, and do so in order to have an 'uncontaminated' response. Such market researchers may, on some occasions, avoid debriefings because they are thought to be unnecessary or that they may get a negative reaction. One empirical study set out to determine whether or not mild deceptions had an adverse effect. Toy et al. (1989) found that participants most commonly reacted well whether or not they received a thorough or a minimal debriefing. This finding is an interesting one but, it must be borne in mind, that it applies to market research, and it applies to non-threatening participation. Despite those qualification it is a worthy result to note.

The clear guiding principle here is to assume that deception may be harmful, and is to be avoided. In those very rare cases where it is deemed to be necessary a strong justification for its use needs to be 
made: that justification should also include the reasons why some other creative means has not been sought to obviate the need for deceit.

Rather than using direct deception one could tell those who volunteered that some of them would receive a dummy treatment (say, a training program) but the reason for not telling them to which group they belonged was to ensure that expectations did not influence the result. In any case they need to be informed at the end which group they belonged to, and in the event that a treatment was effective, be provided with the benefits as a bonus for being participants.

The provision of benefits to a control group also occurs in double blind studies. In such studies there is a real prospect that the experimental intervention (a training program, say) could turn out to have significant advantages. In that sense depriving the control group of that benefit is a negative point. If it turns out that the experimental intervention is beneficial, as before, redress could be effected by offering the control group members the benefit of the session experienced by the experimental group. This would be seen to be a balanced and rewarding response to those kind enough to give their time and input.

\section{Consent}

Out of the Nuremberg trials one clear principle that did emerge was that of consent. This may take various forms from tacit to explicit. What it does mean in practice is that potential participants must be assured, and be confident, in the belief that there is no duress on them to participate. Declining to participate should never carry negative consequences.

To ensure that participation is voluntary there must be a written explanatory note. It will say, for example, who the researchers are; what issue they are addressing; what sort of participant they are seeking; how long it will take to be a participant; and whether or not expense reimbursement is provided. That information sheet will also assure potential participants that there will be no negative consequences for declining. Although it is not universal, there will be a form that participants sign, saying that they have read the information sheet. It is commonplace to require that where a consent form is signed it is witnessed by an independent person, and that a means of locating that witness is recorded (an email address or a telephone number, at least). In the experience of the writers some explanatory sheets are so poorly expressed that they do not communicate. The common form of difficulty is that of not matching the prose level to the level of the prospective reader. For example, language appropriate to those with higher degrees is not a language appropriate to those who farm in remote communities. In cases of doubt, use the simpler form.

Consent to use the research data is usually implied as being for that purpose. What does concern some committees is that the data may be used for another purpose, and at a time far removed from the present. The guiding principle here is openness and honesty. If the data might be used later, and for another purpose, the potential participant must be told, and give consent.

Consent to participate might, in some circumstances, bring dangers unforseen by a participant. Someone conducting a lengthy and personal interview might, for example, receive a revelation of a criminal offence that has not been adjudicated. If it is a serious offence or potential offence then the recipient of that confidence might have a legal obligation to report it to the police. To do so would destroy confidence in promise of anonymity: not to report is in breach of a legal obligation. Here the principle is that of warning. The wording would be something like 'Do not tell me anything about any offence that you have committed that has not been dealt with by a court. If you do I will have to report it'.

A final issue here is that of the use of special groups in research. Among such special groups are minors, certain ethnic minorities, prisoners, and the intellectually underprivileged. Most research ethics committees ask special questions about the use of such groups, and set special requirements before agreeing to their use. 


\section{Feedback}

The notion of feedback is an essential component of research. It is commonplace to hear participants complain that they gave their time and never really knew of the outcome. To this end it would be a common courtesy to ensure that, at the end of the project, all participants receive a thank-you note, and a one page summary reiterating the point of the project, and the general findings. In some cases the promise of anonymity, or the wish not to be contacted, may over-ride that consideration. It is recommended that summary feedback be the norm, and exceptions made only for cases such as those just above.

\section{Debriefing Counselling}

In some studies the interventions or questioning have the potential to be confusing or detrimental to the participant. In such cases a counselling debriefing session may be of help. One of the difficulties here is that the person chosen to alleviate the concerns raised by participation may be an interested party (the researcher is the most common one here). Such a person may lack both the skills and independence to perform effectively. To this end it is a valuable policy to have a qualified independent professional available in case of need - a registered psychologist for example. A counselling session would be appropriate where, say, a participant became very emotional and upset because the questions asked by the researcher triggered a traumatic memory.

One of the signal advantages of debriefing, apart from offsetting possible harmful effects on the participant, is that of researcher benefit. Frohlich et al. (1999) have argued that much may be learned from participants about their experiences in the study. That also assists the researchers to have a better understanding of external validity.

What is important here is to distinguish between debriefing and essential counselling. At its simplest, a debriefing would be an explanation of what the research was about. If it was not appropriate to give the participants a full explanation at the beginning in case it influenced their expectation, and thus their responses, then an explanation at the end is essential.

\section{Conclusions}

This article aimed to alert researchers to some of the issues that might impede progress of an application through an ethics research committee. It is noted that ethics committees most commonly have a guiding and enabling brief, rather than one which impedes. Such committees should be seen in that constructive light.

In completing an ethics application form it is essential to address the 'Advice to applicants' that invariably accompanies a written application. Applicants could profitably bear in mind the way that committee members might approach an application. They are unlikely to know as much about the research as does the applicant, and so the researchers' assumptions waste the committee's time. A simple instance is the prolific use of specialist acronyms that the committee is unlikely to understand. The target reader is an ethics expert - not an expert in any specific research project.

In brief outline given here the advice is: bear in mind the target reader; follow the advice given with the application; do not write an extensive essay, but be concise and to the point; in an information sheet use language that is appropriate to the potential participant. It is a good idea to have an experienced colleague check any application before filing. The principles outlined in this article are intended to provide and insight into how research ethics applications are viewed. By attention to the outline given above an application may be expedited. With such attention to the principles and practices of research ethics committees the experience should be both more pleasurable and more efficient. 


\section{References}

Brown J S, Schonfeld T L, and Gordon B G (2006). You may have already won ...: an examination of the use of lottery payments in research. Ethics and human research. 28 (1) 12-16

DEST definition of research. http://www.canberra.edu.au/research/funding/dest-definition (viewed 13th March 2007).

Epley N \& Huff C (1998). Suspicion, affective response, and educational benefit as a result of deception in psychology research. Personality and social psychology bulletin. 24 (7) 759-768

Frohlich N \& Oppenheimer J (1999). What we learned when we stopped and listened. Simulation and gaming. 30 (4) 494-497

Fry C L, Ritter A, Baldwin S, Bowen K J, Gardiner P, Holt T, Jenkinson R, and Johnston J. (2005). Paying research participants: a study of current practices in Australia. Journal of medical ethics. 31 (9) $542-547$

National Health and Medical Research Council. National Ethics Application Form (NEAF). https://www.neaf.gov.au/Default.aspx

Nuremberg Code: http://ohsr.od.nih.gov/guidelines/nuremberg.html. Viewed 27th Feb. 2007

Schonfeld T L, Brown J S, Weniger M, and Gordon B (2003). Research involving the homeless: arguments against payment in kind (PinK). Ethics and human research. 25 (5) 17-20

Toy D, Olsen J \& Wright L (1989). Effects of debriefing in marketing research involving 'mild' deceptions. Psychology and marketing. 6 (1) 69-85 
